\title{
PENGARUH INFLASI DAN PERTUMBUHAN EKONOMI TERHADAP LABA BANK UMUM YANG TERDAFTAR DI BEI
}

\author{
Effendy Sutejo \\ Program Studi Magister Manajemen Universitas Tarumanagara \\ effendysutejo@gmail.com
}

\begin{abstract}
The aim of this research was to analyze the influence of inflation and gross domestic product (GDP) growth against net interest margin (NIM). Population of this research is all commercial banks listed in Indonesia Stock Exchange (IDX) from 2015 to 2017. Samples collected by purposive sampling method. After passed the purposive sampling phase, 32 commercial banks have been selected as samples, which then categorized into 2 groups, small cap banks and big cap banks. The test results showed that inflation does not have significant effect on NIM of small cap banks. On the other hand, inflation has a significant and negative effect on NIM of big cap banks. The test results also showed that GDP growth does not have significant effect on neither small cap banks nor big cap banks.
\end{abstract}

Keywords : Inflation, Gross Domestic Product (GDP) Growth, Net Interest Margin

\begin{abstract}
Abstrak : Tujuan penelitian ini adalah untuk mengidentifikasi apakah inflasi dan pertumbuhan produk domestik bruto (PDB) memiliki pengaruh yang signifikan terhadap net interest margin (NIM). Populasi penelitian adalah bank umum yang terdaftar di pasar saham periode 20152017. Pengambilan sampel dilakukan dengan metode purposive sampling, Berdasarkan kriteria yang telah ditentukan, sampel yang digunakan sebanyak 32 bank umum yang kemudian dibagi menjadi 2 kelompok, yaitu kelompok bank kecil dan kelompok bank besar. Hasil penelitian menunjukkan bahwa inflasi tidak memiliki pengaruh yang signifikan terhadap NIM kelompok bank kecil, tetapi memiliki pengaruh yang signifikan dan negatif terhadap kelompok bank besar. Sedangkan pertumbuhan PDB tidak memiliki pengaruh yang signifikan terhadap NIM baik kelompok bank kecil maupun kelompok bank besar.
\end{abstract}

Keywords : inflation, Gross Domestic Product (GDP) Growth, Net Interest Margin.

\section{PENDAHULUAN}

Sektor perbankan memegang peranan penting dalam pertumbuhan ekonomi, yaitu sebagai perantara pihak yang kelebihan dana dengan pihak yang membutuhkan dana sesuai Undang-Undang Republik Indonesia nomor 10 tahun 1998 (fungsi intermediasi). Penting bagi bank untuk menjalankan fungsi intermediasinya dengan biaya seminimal mungkin dalam rangka meningkatkan kesejahteraan sosial. Menurut Brock dan Suarez (2000), net interest margin (NIM), yaitu selisih antara pendapatan bunga yang diperoleh bank dengan beban bunga yang harus ditanggung oleh bank, merupakan salah satu indikator menilai efisiensi intermediasi keuangan, semakin rendah NIM, maka bank dianggap semakin efisien dalam menjalankan fungsi intermediasinya.

Namun demikian, menurut Saunders dan Schumacher (2000), meskipun tingginya NIM biasanya dihubungkan dengan inefisiensi, NIM juga berkontribusi memperkuat sistem perbankan. Hal ini dapat terjadi saat keuntungan yang didapat dari spread yang tinggi disalurkan menjadi modal. Tingginya imbal hasil yang didapatkan dari pemberian kredit serta masih rendahnya proporsi pendapatan yang berasal dari fee-based income membuat bank di Indonesia mengandalkan NIM untuk memperoleh profitabilitas yang tinggi. Oleh karena itu terdapat konflik kepentingan antara biaya intermediasi yang diharapkan rendah dengan keinginan bank untuk memperoleh profitabilitas yang tinggi. 
Berdasarkan Statistik Perbankan Indonesia (SPI) yang diterbitkan oleh Otoritas Jasa Keuangan (OJK), NIM dari bank umum konvensional di Indonesia berada di angka 5,19\% per Januari 2018. Jika dibandingkan dengan periode yang sama, NIM perbankan di Indonesia menduduki peringkat tertinggi di Asia Tenggara, di mana umumnya NIM perbankan di Asia Tenggara berada pada kisaran $2 \%$ sampai $4 \%$. Sudah sewajarnya untuk meningkatkan perhatian pada bagaimana NIM yang relatif tinggi cenderung berpengaruh negatif terhadap potensi pertumbuhan perekonomian Indonesia.

Tujuan penelitian ini adalah untuk mengidentifikasi apakah inflasi dan pertumbuhan Produk Domestik Bruto (PDB) memiliki pengaruh yang signifikan terhadap NIM. Dengan demikian diharapkan bank dapat mengambil keputusan terbaik terkait faktor-faktor yang mempengaruhi NIM sehingga dapat meningkatkan efisiensi intermediasi keuangan sekaligus tetap menjaga profitabilitas bank yang optimal.

\section{TINJAUAN PUSTAKA}

Berdasarkan Surat Edaran Bank Indonesia Nomor 6/23/DPNP tanggal 31 Mei 2004, NIM merupakan perbandingan antara pendapatan bunga bersih terhadap rata-rata aktiva produktifnya. Pendapatan bunga bersih diperoleh dari selisih antara bunga pinjaman yang diperoleh dari kegiatan penyaluran kreditnya dengan bunga simpanan yang dibayarkan kepada masyarakat karena telah menyimpan dananya di bank. NIM juga merupakan salah satu rasio rentabilitas yang penting, yaitu rasio untuk kemampuan bank dalam menghasilkan laba.

Penelitian mengenai NIM diawali oleh Ho dan Saunders pada tahun 1981. Hasil penelitiannya menunjukkan bahwa perolehan NIM bank tergantung pada keengganan bank menghadapi risiko (risk aversion), ukuran transaksi bank, tingkat suku bunga dan tingkat kompetisi pasar. Kemudian, penelitian tentang NIM dikembangkan oleh Maudos dan De Guevara (2004) yang menyertakan biaya operasional (efisiensi) dalam modelnya. Selanjutnya, sebagian besar penelitian mengenai NIM menggunakan variabel likuiditas, risiko kredit, modal, efisiensi, ukuran bank dan beberapa faktor makroekonomi seperti inflasi dan pertumbuhan PDB.

Menurut Perry (1992), pengaruh inflasi terhadap NIM bank tergantung pada antisipasi bank terhadap pergerakan inflasi di masa yang akan datang. Tingkat inflasi yang diantisipasi dapat meningkatkan NIM bank selama bank bisa menyesuaikan tingkat suku bunga dengan tepat untuk menghasilkan keuntungan. Sementara perubahan tingkat inflasi yang tidak diantisipasi dapat meningkatkan biaya untuk menarik dana masyarakat karena kenaikan inflasi akan menurunkan imbal hasil dari bunga saat ini, sehingga nasabah cenderung memilih investasi dengan imbal hasil yang lebih tinggi seperti saham atau sekuritas lain. Untuk menarik nasabah agar menyimpan dananya di bank, bank harus meningkatkan bunga yang mengakibatkan peningkatan beban bunga dan menurunkan NIM. Penelitian yang dilakukan oleh Kunt et al. (1999) menemukan hubungan yang positif antara inflasi dengan NIM bankbank tersebar di 80 negara. Sedangkan, penelitian yang dilakukan oleh Abreu dan Mendes (2003) menemukan hubungan yang negatif antara inflasi dengan NIM bank-bank yang tersebar di Portugal, Spanyol, Perancis dan Jerman.

Menurut Plakalovic dan Alihodzic (2015), perkembangan aktivitas ekonomi yang baik dapat diketahui melalui pertumbungan PDB positif, memicu tingginya permintaan akan kredit dan semakin sedikitnya kredit bermasalah maka marjin bank akan semakin tinggi sehingga berimbas terhadap meningkatnya NIM. Sedangkan menurut Gul et al. (2011), pertumbuhan ekonomi (pertumbuhan PDB) yang meningkat akan meningkatkan permintaan kredit. Tingginya permintaan kredit menyebabkan risiko kredit akan bertambah dan apabila bank tidak mampu mengantisipasi risiko kredit seperti risiko gagal bayar, maka pendapatan bunga bank akan menurun sehingga NIM bank juga akan menurun. Penelitian yang dilakukan oleh Kunt et al. (1999) menemukan hubungan yang negatif antara pertumbuhan PDB dengan NIM, 
sedangkan penelitian yang dilakukan oleh Roman (2009) tidak menemukan adanya hubungan antara pertumbuhan PDB dengan NIM.

\section{Kerangka Pemikiran}

Berdasarkan latar belakang, tujuan penelitian dan tinjauan pustaka, maka variabelvariabel dalam penelitian ini dapat dirumuskan dalam suatu kerangka pemikiran sebagai berikut:

Gambar 1. Kerangka Pemikiran

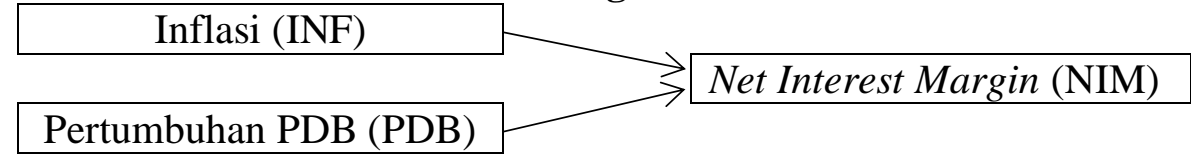

\section{Hipotesis Penelitian}

Berdasarkan kerangka pemikiran di atas, maka hipotesis yang akan diuji dalam penelitian ini adalah:

$\mathrm{H}_{1}$ : Inflasi memiliki pengaruh yang signifikan terhadap NIM.

$\mathrm{H}_{2}$ : Pertumbuhan PDB memiliki pengaruh yang signifikan terhadap NIM.

\section{METODE PENELITIAN}

Variabel Penelitian

Variabel independen yang digunakan dalam penelitian ini adalah inflasi dan pertumbuhan PDB, sedangkan variabel dependen yang digunakan dalam penelitian ini adalah NIM. Adapun definisi operasional variabel dijabarkan pada Tabel 1:

\section{Tabel 1. Definisi Operasional Variabel}

\begin{tabular}{|l|l|l|l|}
\hline No. & Variabel & Definisi & Pengukuran \\
\hline 1 & $\begin{array}{l}\text { Net Interest } \\
\text { Margin (NIM) }\end{array}$ & $\begin{array}{l}\text { Rasio pendapatan bunga } \\
\text { bersih dengan rata-rata } \\
\text { aktiva produktif }\end{array}$ & $\mathrm{NIM}=\frac{\text { Pendapatan Bunga Bersih }}{\text { Aktiva Produktif }}$ \\
\hline 2 & Inflasi (INF) & $\begin{array}{l}\text { Tingkat perubahan inflasi } \\
\text { pada periode satu tahun } \\
\text { dibandingkan dengan } \\
\text { periode tahun sebelumnya }\end{array}$ & (INF $\left._{\mathrm{n}+1}-\mathrm{INF}_{\mathrm{n}}\right) / \mathrm{INF}_{\mathrm{n}}$ \\
\hline 3 & $\begin{array}{l}\text { Pertumbuhan PDB } \\
\text { (PDB) }\end{array}$ & $\begin{array}{l}\text { Tingkat pertumbuhan } \\
\text { PDB pada periode satu } \\
\text { tahun dibandingkan } \\
\text { dengan periode tahun } \\
\text { sebelumnya }\end{array}$ & PDB $\left._{\mathrm{n}+1}-\mathrm{PDB}_{\mathrm{n}}\right) / \mathrm{PDB}_{\mathrm{n}}$ \\
\hline
\end{tabular}

\section{Metode Pengumpulan Data}

Jenis data yang digunakan adalah data sekunder. Dalam penelitian ini, data diperoleh dari laporan keuangan tahunan sektor perbankan yang dipublikasikan di pasar saham periode 20152017 melalui website www.idx.co.id, serta tingkat inflasi dan pertumbuhan PDB yang dipublikasi oleh BI melalui website www.bi.go.id.

\section{Populasi dan Sampel Penelitian}

Populasi penelitian sebanyak 43 bank umum yang terdaftar di pasar saham periode 20152017. Teknik pengambilan sampel dalam penelitian ini adalah purposive sampling. Beberapa kriteria yang ditentukan dalam penelitian ini adalah:

1. Bank umum yang terdaftar di pasar saham dan mempublikasikan laporan keuangan tahunan secara lengkap periode 2015-2017.

2. Bank yang tidak mengalami kenaikan atau penurunan BUKU selama periode 2015-2017. 
Berdasarkan kriteria yang telah ditentukan, maka didapatkan sampel sebanyak 32 bank dari total 43 bank umum, kemudian sampel tersebut dibagi menjadi 2 kelompok, yaitu kelompok bank kecil dan kelompok bank besar. Kelompok bank kecil merupakan gabungan 4 sampel bank BUKU 1 dan 13 sampel bank BUKU 2. Sedangkan kelompok bank besar merupakan gabungan 11 sampel bank BUKU 3 dan 4 sampel bank BUKU 4.

\section{Metode Analisa}

Analisis data yang digunakan adalah analisis data kuantitatif. Dalam penelitian ini digunakan model analisis regresi linier berganda dengan data panel. Persamaan regresi linier berganda dalam penelitian ini yaitu :

Dimana:

$$
\mathrm{NIM}_{\mathrm{it}}=\mathrm{C}+\boldsymbol{\beta 1} \mathrm{INF}_{\mathrm{it}}+\beta 2 \mathrm{PDB}_{\mathrm{it}}+\varepsilon_{\mathrm{it}}
$$

$$
\begin{array}{ll}
\mathrm{NIM} & =\text { Net Interest Margin } \\
\mathrm{C} & =\text { Konstanta } \\
\beta 1-\beta 2 & =\text { Koefisien } \\
\mathrm{INF} & =\text { Inflasi } \\
\mathrm{PDB} & =\text { Pertumbuhan PDB } \\
\varepsilon & =\text { Error }
\end{array}
$$

\section{HASIL DAN PEMBAHASAN}

Hasil uji Chow dan uji Hausman menyatakan Random Effect Model merupakan pendekatan terbaik untuk mengestimasi model dalam penelitian ini. Berikut merupakan hasil regresi data panel:

Tabel 2. Rangkuman Hasil Regresi Kelompok Bank Kecil

\begin{tabular}{ccccc}
\hline \hline Variable & Coefficient & Std. Error & t-Statistic & Prob. \\
\hline \hline C & 0.107423 & 0.058962 & 1.821908 & 0.0747 \\
INF? & 0.034473 & 0.400948 & 0.085978 & 0.9318 \\
PDB? & -1.332003 & 1.183596 & -1.125386 & 0.2660 \\
\hline \hline R-squared & 0.025786 & F-statistic & 0.635257 \\
Adjusted R-squared & -0.014806 & Prob(F-statistic) & 0.534195 \\
\hline \hline
\end{tabular}

Tabel 3. Rangkuman Hasil Regresi Kelompok Bank Besar

\begin{tabular}{ccccc}
\hline \hline Variable & Coefficient & Std. Error & t-Statistic & Prob. \\
& & & & \\
\hline \hline C & 0.058471 & 0.024988 & 2.339949 & 0.0241 \\
INF? & -0.788987 & 0.166546 & -4.737360 & 0.0000 \\
PDB? & 0.570895 & 0.491643 & 1.161199 & 0.2521 \\
\hline \hline R-squared & 0.351187 & F-statistic & 11.36681 \\
Adjusted R-squared & 0.320291 & Prob(F-statistic) & 0.000113 \\
\hline \hline
\end{tabular}

Berdasarkan Tabel 2 dan Tabel 3, maka diperoleh persamaan regresi data panel sebagai berikut :

Kelompok Bank Kecil $\quad$ NIM $=0,107423+0,034473$ INFLASI $-1,332003$ PDB

Kelompok Bank Besar $\quad \mathrm{NIM}=0,058471-0,788987$ INFLASI + 0,570895 PDB 


\section{Pengaruh inflasi terhadap NIM}

Pada kelompok bank kecil, hasil penelitian menunjukkan bahwa inflasi tidak memiliki pengaruh yang signifikan terhadap NIM. Sedangkan pada kelompok bank besar, hasil penelitian menunjukkan bahwa inflasi memiliki pengaruh yang signifikan dan negatif terhadap NIM. Hubungan yang negatif ini sesuai dengan teori yang dikemukakan Perry (1992), bahwa jika bank gagal mengantisipasi inflasi, pengaruh terhadap NIM akan negatif, karena bank terlalu lambat menyesuaikan suku bunga mereka, sehingga peningkatan biaya (beban bunga) lebih cepat dibanding peningkatan keuntungan.

Hasil penelitian menunjukkan bahwa bank umum BUKU 1 dan BUKU 2 yang terdaftar di pasar saham mampu mengantisipasi fluktuasi tingkat inflasi pada tahun 2015 sampai 2017 dengan baik, sehingga fluktuasi tingkat inflasi tidak mempengaruhi margin bunga bersih mereka. Lain halnya dengan bank umum BUKU 3 dan BUKU 4 yang ternyata tidak mampu mengantisipasi fluktuasi tingkat inflasi pada tahun 2015-2017, sehingga fluktuasi tingkat inflasi mempengaruhi margin bunga bersih mereka secara negatif, hasil ini konsisten dengan penelitian yang dilakukan oleh Abreu dan Mendes (2003).

\section{Pengaruh pertumbuhan PDB terhadap NIM}

Hasil penelitian ini konsisten dengan penelitian yang dilakukan oleh Roman (2009), di mana pertumbuhan PDB tidak memiliki pengaruh yang signifikan terhadap NIM baik pada kelompok bank kecil maupun kelompok bank besar. Hal ini bila dikaitkan dengan penelitian yang dilakukan oleh Gul et al. (2011) serta Plakalovic \& Alihodzic (2015), adalah baik bank umum BUKU 1 dan BUKU 2 maupun bank umum BUKU 3 dan BUKU 4 dapat mengantisipasi adanya risiko kredit seperti risiko gagal bayar dari fluktuasi pertumbuhan ekonomi pada tahun 2015 sampai 2017, sehingga fluktuasi pertumbuhan PDB tidak mempengaruhi NIM.

\section{PENUTUP \\ Kesimpulan}

Penelitian ini bertujuan untuk menguji pengaruh inflasi dan pertumbuhan PDB terhadap NIM. Berdasarkan hasil analisis regresi data panel yang dilakukan pada 17 sampel kelompok bank kecil serta 15 sampel kelompok bank besar, maka dapat diambil kesimpulan bahwa:

1. Inflasi tidak memiliki pengaruh yang signifikan terhadap NIM kelompok bank kecil, sedangkan inflasi memiliki pengaruh yang negatif dan signifikan terhadap NIM kelompok bank besar. Dapat disimpulkan bahwa hipotesis 1 ditolak untuk bank umum BUKU 1 dan BUKU 2, tetapi hipotesis 1 diterima untuk bank BUKU 3 dan BUKU 4.

2. Pertumbuhan PDB tidak memiliki pengaruh yang signifikan terhadap NIM baik pada kelompok bank kecil maupun pada kelompok bank besar. Dapat disimpulkan bahwa hipotesis 2 ditolak untuk bank BUKU 1, BUKU 2, BUKU 3, serta BUKU 4.

\section{Saran}

Bagi perbankan, hendaknya meningkatkan antisipasi bank terhadap pergerakan tingkat inflasi di masa yang akan datang, sehingga fluktuasi tingkat inflasi nantinya tidak mempengaruhi profitabilitas perbankan, di samping itu industri perbankan juga perlu meningkatkan proporsi pendapatan yang berasal dari fee-based income sehingga tidak hanya mengandalkan NIM untuk memperoleh keuntungan.

Bagi regulator, melalui penelitian ini diketahui bahwa tingkat inflasi merupakan suatu faktor yang mempengaruhi NIM industri perbankan. Penting untuk pemerintah menjaga tingkat inflasi agar tercipta siklus ekonomi yang baik dan mencegah dampak sistemik.

Bagi penelitian selanjutnya, dengan menggunakan variabel yang sama, populasi penelitian ini dapat dikembangkan dengan mempertimbangkan banyaknya bank-bank umum yang hingga saat ini belum terdaftar di pasar saham, atau dapat juga dikembangkan dengan menambahkan variabel independen lainnya terutama dari faktor internal perbankan itu sendiri. 


\section{REFERENSI}

Abreu, M. and Mendes, V. 2003. Do macro-financial variable matter for European bank interest margins and profitability. Financial Management Association International.

Brock, P. L. and Suarez, L.R. 2000. Understanding the Behaviour of Bank Spreads in Latin America. Journal of Development Economics, 63, 113 - 34.

Demirgüç-Kunt, A. and Huizinga, H. 1999. Determinants of commercial bank interest margins and profitability: some international evidence. The World Bank Economic Review, 13(2), pp.379-408.

Gul, Schrish., Faiza, I., dan Khalid, Z. 2011. Factors Affecting Bank Profitability in Pakistan. The Romanian Economic Journal, 14(39), 61-87.

Ho, S.Y., and Saunders, A., 1981. The Determinants of Bank Interest Margins: Theory and Empirical Evidence. Journal of Financial and Quantitative Analysis, XVI, 4.

Horvath, Roman. 2009. The Determinants of the Interest Rate Margins of Czech Banks. Czech Journal of Economics and Finance, 59, 2009, No. 2.

Maudos, J., and Fernandez de Guevara, J. 2004. Factors explaining the interest margin in the banking sectors of the European Union. Journal of Banking \& Finance, 28:2259-2281.

Nachrowi, N. D. dan Usman, H. Pendekatan Populer dan Praktis EKONOMETRIKA untuk Analisis Ekonomi dan Keuangan. Jakarta: Lembaga Penerbit Fakultas Ekonomi Universitas Indonesia, 2006.

Peraturan Bank Indonesia No. 6/10/PBI/2004 tanggal 12 April 2004, tentang Sistem Penilaian Tingkat Kesehatan Bank Umum.

Perry, P. 1992. Do Banks Gain or Lose from Inflation. Journal of Retail Banking 14 (2), 2540.

Plakalovic, N. and Alihodzic, A., 2015. Determinants of Credit Growth to Nonfinancial Companies in B\&H. Industrija, 43(1): 133-153.

Republik Indonesia, 1998. Undang-Undang Nomor 10 Tahun 1998 tentang Undang-Undang Perubahan Undang-Undang Nomor 7 Tahun 1992 tentang Perbankan.

Saunders, A. and Schumacher, L., 2000. The Determinants of Bank Interest Rate Margins: An International Study. Journal of International Money and Finance 19(6), 813-832.

Surat Edaran Bank Indonesia No. 6/23/DPNP tanggal 31 Mei 2004, tentang Sistem Penilaian Tingkat Kesehatan Bank Umum. 